\title{
Epilogue
}

\section{Healthcare Costs or Investments?}

We are currently embroiled in two debates involving healthcare. One debate involves how the costs of making healthcare available to everyone should be apportioned among individuals, employers, and the government. The second debate concerns how to achieve reductions in the high costs of healthcare to provide the best value. Both debates have to be resolved effectively to achieve our goals. Only addressing one - by, for example, solely making everyone insured - may worsen our cost problems by having many more people demanding very expensive, and sometimes marginally effective care.

Of course, both of these endeavors will require money. How much are we willing to spend to have a healthy, educated, and productive population? There is an underlying subtlety to this question. Is healthcare an expense or an investment? One could argue that it is an investment in human capital that will provide future returns in terms of a productive, competitive workforce and income tax revenues, as well as reduced healthcare costs.

As a savvy investor, we would like the value of this human capital to exceed its cost. As noted above, we have been vigorously debating costs. What about the value of human capital investments? There are data, methods, and tools for estimating the economic value of investments in people's training, education, safety, health, and productivity. We know how to estimate the savings in future healthcare costs that can be achieved by investing now in prevention and early treatments of chronic disease for example.

The difficulty is not our inability to estimate the economic value of investing in healthcare. The problem is that there is no place to put the numbers once we have them. The costs of these investments appear on the national Income Statement, but the value of these investments do not appear on the national Balance Sheet. The reason is simple - we do not maintain a Balance Sheet. Congress has a checkbook, but not a full set of financial statements.

Consequently, in these two ongoing debates, no one at the table owns the future. No one feels responsible for assuring that we have the human capital assets we need to be competitive in Tom Friedman's hot, flat and crowded world. As a result, there is no felt need for a Balance Sheet on which to tally the value of these human capital assets. Our inadequate accounting system is keeping us from making the investments we need to make to assure the standard of living to which we aspire.

We believe that some combination of the Office of Management of the Budget, Congressional Budget Office, and General Accountability Office should take the lead in adding a Balance Sheet to the national Income Statement. It could begin as an oversight scorecard and then, with experience, become an element of the decision making process. This would result in healthcare investments having much greater asset values than "bridges to nowhere."

We are all better off if everyone is healthy, educated, and productive. The fact that we send our children to school, exercise and try to eat a healthy diet, and pursue advanced education all attest to this philosophy. We know how to balance the near-term and long-term. For instance, how much are you willing to spend on your monthly utility bill? Less the better is our response. How much are you willing to "spend" on your 401(k)? More the better is our answer. 
The healthcare debates need to shift from minimizing the costs of our utility bills to maximizing the value of our $401(\mathrm{k}) \mathrm{s}$. These debates also need to broaden to include education. While productivity may primarily involve private sector investments, an educated populace will make it easier to have a healthy populace. We need human capital that is both well and smart.

William B. Rouse Executive Director of the Tennenbaum Institute at Georgia Institute of Technology

E-mail: bill.rouse@ti.gatech.edu

Michael E. Johns Chancellor of Emory University and former CEO of Emory Health Sciences E-mail: mmejohns@emory.edu

Denis A. Cortese President and CEO of Mayo Clinic

E-mail: cortese.denis@mayo.edu 